\title{
The myths and realities of hemochromatosis
}

\author{
Melanie D Beaton MD, Paul C Adams MD
}

MD Beaton, PC Adams. The myths and realities of hemochromatosis. Can J Gastroenterol 2007;21(2):101-104.

Hemochromatosis is a common genetic condition and yet there are still a number of misperceptions surrounding the diagnosis and management of this condition. Hemochromatosis affects both men and women. Typical patients do not have alcoholism or viral hepatitis, and often have normal liver enzymes. Clinical expression is highly variable. Genetic testing is widely available and particularly useful in family studies. Hemochromatosis can be readily diagnosed and treated. The purpose of the present review is to address the medical myths and misconceptions of hemochromatosis.

\section{Les mythes et les réalités de l'hémochromatose}

\begin{abstract}
L'hémochromatose est un trouble génétique courant, mais il existe encore un certain nombre de conceptions erronées au sujet de son diagnostic et de sa prise en charge. L'hémochromatose touche à la fois les hommes et les femmes. D'ordinaire, les patients ne sont pas alcooliques et ne souffrent pas d'hépatite virale, et leurs enzymes hépatiques sont souvent normaux. L'expression clinique de la maladie est hautement variable. Les tests génétiques sont facilement accessibles et particulièrement utiles dans le cadre d'études familiales. L'hémochromatose peut être diagnostiquée et traitée rapidement. La présente analyse vise à examiner les mythes et les conceptions erronées à son sujet.
\end{abstract}

Key Words: Genetic testing; Hemochromatosis; Iron

$T_{\mathrm{in}}^{\mathrm{h}}$. he medical landscape is vast with an expanding array of information about old and new diseases. Thus, it becomes an insurmountable task for any physician to be up-to-date on all of the recent developments in modern medicine. For most physicians, it is acceptable to inform patients that they may not have all of the current information about their medical condition. This may lead to further study in textbooks or increasingly on the Internet, or they may seek a referral to a specialist with expertise in this area. In the present review, some of the common myths and misconceptions of hemochromatosis are explored.

\section{HEMOCHROMATOSIS MYTHS}

\section{Hemochromatosis is rare}

A large population study (1) has demonstrated that one in 227 Caucasians in North America is homozygous for the C282Y mutation of the hemochromatosis gene. This is the typical genetic pattern seen in over $90 \%$ of typical patients; however, there are many $\mathrm{C} 282 \mathrm{Y}$ homozygotes who are asymptomatic. Approximately, 20\% of male homozygotes and $50 \%$ of female homozygotes will have normal serum ferritin levels. If the disease is defined based on symptoms, the prevalence would be much lower, and because the symptoms may be nonspecific, it is more difficult to assess the prevalence of symptomatic hemochromatosis. This differs significantly between referred patients and participants in population screening studies. There has also been considerable debate about whether the genotype should be used to define hemochromatosis or whether it should be based on the presence of iron overload, independent of genotype (2). The bottom line is that this condition is extremely common within the Caucasian population and physicians should have a low index of suspicion when ordering screening tests, such as the transferrin saturation test and the serum ferritin test, for iron overload.

\begin{abstract}
Women are not affected by hemochromatosis
As an autosomal recessive condition, hemochromatosis affects men and women equally in regard to the inheritance of the hemochromatosis gene. It has been considered that the effects of menses and pregnancy will significantly offset the lifelong accumulation of iron with tissue injury. A study (3) of 176 female hemochromatosis patients, matched to 176 male patients with respect to birth year, demonstrated similar hepatic iron concentrations in both sexes. However, male patients had a higher prevalence of cirrhosis compared with female patients (26\% versus $14 \%$ ). Cirrhosis in a female hemochromatosis patient has rarely been discovered in a population screening study. It is also important to assess women so that genetic counselling can be provided to their children and siblings.
\end{abstract}

\section{Most hemochromatosis patients are alcoholics}

The misconception that most hemochromatosis patients are alcoholics stems from the fact that most alcoholics have elevations in serum ferritin levels and some patients with alcoholic liver disease have increased iron deposition in the liver (alcoholic siderosis). This latter condition was widely reported from the Boston area in the 1960s (4) and likely 'contaminated' the hemochromatosis literature with patients who did not actually have genetic hemochromatosis. Studies $(5,6)$ on the prevalence of alcoholism based on hemochromatosis pedigrees have shown no increased evidence of alcoholism. The genetic test for hemochromatosis remains a powerful diagnostic tool to help separate alcoholic liver disease from hemochromatosis.

Many hemochromatosis patients have chronic viral hepatitis The prevalence of both hepatitis B virus (HBV) and hepatitis C virus $(\mathrm{HCV})$ is not consistently higher in hemochromatosis

Department of Medicine, London Health Sciences Centre, London, Ontario

Correspondence: Dr Paul C Adams, Department of Medicine, London Health Sciences Centre, 339 Windermere Road, London,

Ontario N6A 5A5. Telephone 519-685-8500 ext 35375, fax 519-663-3549, e-mail padams@uwo.ca

Received for publication May 16, 2006. Accepted June 12, 2006 
patients. A screening study (7) that identified $302 \mathrm{C} 282 \mathrm{Y}$ homozygotes found one case of concomitant $\mathrm{HCV}$ and none with HBV. Much like alcoholic liver disease, both chronic HBV and HCV have been associated with elevations in serum ferritin levels and less commonly associated with increases in hepatic iron concentrations with advanced liver disease (8). Genetic testing is useful in this setting to differentiate hemochromatosis from iron abnormalities secondary to chronic viral hepatitis.

\section{Diabetes is a cardinal feature of hemochromatosis}

Although hemochromatosis was once called 'bronze diabetes', recent population screening studies $(1,9)$ have not demonstrated an increased prevalence of diabetes in C282Y homozygotes compared with a control population. The pathogenesis of diabetes in hemochromatosis is likely multifactorial and can include defects in insulin secretion and insulin resistance $(10,11)$.

\section{Most hemochromatosis patients have elevated liver enzymes}

Although liver disease is the most consistent feature of the disease, hemochromatosis is not an inflammatory liver disease and, therefore, many patients will have normal liver enzymes (12). In a review (13) of 351 C282Y homozygotes from our hemochromatosis clinic at the London Health Sciences Centre in London, Ontario, 277 of 351 (79\%) patients had an aspartate aminotransferase level of less than $40 \mathrm{U} / \mathrm{L}$ and 238 of $351(68 \%)$ patients had an alanine aminotransferase level of less than $40 \mathrm{U} / \mathrm{L}$. It remains prudent to screen patients with unexplained enzyme elevations with transferrin saturation and serum ferritin tests.

\section{Most patients with an elevated serum ferritin level have hemochromatosis}

A population screening study (1) has demonstrated that elevation in serum ferritin levels is seen in approximately $10 \%$ of primary care patients. When these patients are investigated in a referral clinic, only $33 \%$ to $42 \%$ have genetic hemochromatosis. More common causes of increased serum ferritin levels include obesity, fatty liver and daily alcohol consumption (14).

\section{An elevated hemoglobin is common in hemochromatosis}

Some physicians have told patients that they do not have hemochromatosis because their hemoglobin levels are normal. Perhaps this is based on the concept that if iron deficiency reduces hemoglobin, iron excess could increase hemoglobin. A review of $634 \mathrm{C} 282 \mathrm{Y}$ homozygotes at our clinic at the London Health Sciences Centre (London, Ontario) showed a mean hemoglobin level of $145 \pm 13 \mathrm{~g} / \mathrm{L}$, which suggests that polycythemia is not a reliable marker for iron overload.

Hemochromatosis is not a cause of significant liver disease It has been well established that with timely diagnosis and institution of iron depletion therapy, patients with hemochromatosis can be expected to have a prognosis equal to that of controls. However, among patients with severe iron accumulation, the risk of progression to cirrhosis is significant. As in other causes of cirrhosis, morbidity and mortality rates are increased due to the many associated complications of endstage liver disease including the development of hepatocellular carcinoma. However, in the case of cirrhosis due to hemochromatosis, the incidence of hepatocellular carcinoma is significantly higher than that of many other causes of liver disease. Iron overload in hemochromatosis has also been shown to potentiate alcoholic liver disease and may have a similar effect on the course of HCV and nonalcoholic fatty liver disease $(15-17)$. Given that $1.8 \%$ of the population in the United States are HCV-positive and that up to $24 \%$ have nonalcoholic fatty liver disease, the coexistence of these disorders with hemochromatosis is likely to affect a reasonable proportion of our population.

\section{Carriers of the hemochromatosis gene often have iron overload}

It has been common for physicians to tell patients with mild elevations in serum ferritin levels that they may be carriers of the hemochromatosis gene. Mild elevations in serum ferritin levels in the general population are very common and occur in all ethnic groups, so they are unlikely to be explained on the basis of heterozygosity for the hemochromatosis gene. A large population study (1) has now demonstrated that C282Y heterozygotes have iron studies similar to those of the general population. There is an increased prevalence of mild iron overload in compound heterozygotes (C282Y/H63D), and some C282Y heterozygotes may also carry an unidentified second mutation.

\section{Children of hemochromatosis patients are at the highest risk of disease}

The misconception that children of hemochromatosis patients are at the highest risk of disease arises because of a misunderstanding by patients and physicians of the concept of autosomal recessive inheritance. Usually a typical C282Y homozygote has heterozygous parents and so there is a higher risk for siblings. The risk is slightly higher than $25 \%$ because there is a possibility that one of the parents is a homozygote. Children of homozygotes are at a much lower risk because the partner must also carry the $\mathrm{C} 282 \mathrm{Y}$ mutation. Among Caucasian couples, the risk to children is approximately $5 \%$ (18). Genetic testing of children younger than 18 years of age is not recommended because of a number of potential concerns about informed consent and genetic discrimination.

\section{Genetic testing for hemochromatosis is a research tool}

Genetic testing for hemochromatosis has a number of unique characteristics. Unlike most genetic diseases, in hemochromatosis there is a single genetic mutation (C282Y) that explains most typical cases. The test is widely available and can be performed at a relatively low cost. There have been a number of studies (19-21) that have assessed the psychosocial impact of genetic testing for hemochromatosis which have concluded that the test is well accepted by patients and has rarely been associated with insurance discrimination. For these reasons, the genetic test has become one of the most commonly requested tests and is a powerful diagnostic tool that is accessible to most physicians.

\section{Hemochromatosis patients should be on a low-iron diet}

Although dietary iron is the source of excess iron in hemochromatosis, a decrease in dietary iron has not been shown to decrease iron stores in hemochromatosis. All food groups contain iron and most humans will absorb only a small fraction of orally ingested iron. Iron absorption includes 
components from heme and nonheme iron sources (22), and the control or lack of control over these regulatory mechanisms is incompletely understood in hemochromatosis. It has been speculated that a defect in hepcidin, a circulating peptide produced by the liver, is a fundamental defect in hemochromatosis which results in an increase in intestinal iron absorption (23). Iron supplementation of food was introduced in the 1950 s as a marketing tool, and the added iron has poor bioavailability. Generally, vegetarians have lower serum ferritin levels than meat-eating patients but this does not translate into a dietary recommendation (24). The description of bacterial infections from Yersinia (25) and other Vibrio species has led to recommendations to avoid raw shellfish which may be appropriate for all patients rather than just hemochromatosis patients. Hemochromatosis patients are advised to avoid iron supplementation and large doses of supplemental oral vitamin $C$ which may adversely affect some patients with iron overload (26).

\section{Hemochromatosis is a progressive disease}

Because hemochromatosis patients presumably begin absorbing excess iron at birth, it seems intuitive that progressive iron overload over time would occur. However, it has not been possible to show a correlation between liver iron concentration and age in hemochromatosis (27). It has become apparent through various studies, in which genetic testing was performed after many years of observation such as in the Copenhagen Heart Study (28), that many C282Y homozygotes do not have a progressive rise in serum ferritin levels,

\section{REFERENCES}

1. Adams PC, Reboussin DM, Barton JC, et al; Hemochromatosis and Iron Overload Screening (HEIRS) Study Research Investigators. Hemochromatosis and iron-overload screening in a racially diverse population. N Engl J Med 2005;352:1769-78.

2. Adams PC. Hemochromatosis case definition: Out of focus? Nat Clin Gastroenterol Hepatol 2006;3:178-9.

3. Moirand R, Adams PC, Bicheler V, Brissot P, Deugnier Y. Clinical features of genetic hemochromatosis in women compared with men. Ann Intern Med 1997;127:105-10.

4. MacDonald RA. Idiopathic hemochromatosis. Genetic or acquired? Arch Intern Med 1963;112:184-90.

5. Adams PC, Agnew S. Alcoholism in hereditary hemochromatosis revisited: Prevalence and clinical consequences among homozygous siblings. Hepatology 1996;23:724-7.

6. Gleeson D, Evans S, Bradley M, et al. HFE genotypes in decompensated alcoholic liver disease: Phenotypic expression and comparison with heavy drinking and with normal controls. Am J Gastroenterol 2006;101:304-10.

7. Adams PC, Passmore L, Chakrabarti S, et al; Hemochromatosis and Iron Overload Screening Study Research Investigators. Liver diseases in the hemochromatosis and iron overload screening study. Clin Gastroenterol Hepatol 2006;4:918-23.

8. Alla V, Bonkovsky HL. Iron in nonhemochromatotic liver disorders. Semin Liver Dis 2005;25:461-72.

9. Beutler E, Felitti VJ, Koziol JA, Ho NJ, Gelbart T. Penetrance of $845 \mathrm{G} \rightarrow \mathrm{A}(\mathrm{C} 282 \mathrm{Y})$ HFE hereditary haemochromatosis mutation in the USA. Lancet 2002;359:211-8

10. McClain D, Abraham D, Rogers J, et al. High prevalence of abnormal glucose homeostasis secondary to decreased insulin secretion in individuals with hereditary haemochromatosis. Diabetologia 2006;49:1661-9.

11. Hramiak I, Finegood D, Adams PC. Factors affecting glucose tolerance in hereditary hemochromatosis. Clin Invest Med 1997;20:110-8.

12. Lin E, Adams PC. Biochemical liver profile in hemochromatosis. A survey of 100 patients. J Clin Gastroenterol 1991;13:316-20. even without phlebotomy treatment. This is the most likely explanation for the discordance between the high frequency of the hemochromatosis genotype and the relatively low representation of hemochromatosis in liver transplant registries (29) or in death certificate data (30). There have been patients who have refused phlebotomy therapy and have been observed over many years to not have any changes in their serum ferritin levels. Phlebotomy therapy has never been subjected to a randomized trial. The strongest supporting evidence for a beneficial effect of phlebotomy is the improvement of liver fibrosis that has been demonstrated on serial liver biopsies in hemochromatosis patients (31). Maintenance therapy is even less established following iron depletion, and many patients will not demonstrate any evidence of iron reaccumulation after many years of observation (32). Many patients enjoy the concept of continuous therapy for hemochromatosis and these patients can be encouraged to be voluntary blood donors several times per year (33). If they are ineligible, an annual ferritin determination is a reasonable alternative to guide maintenance therapy.

\section{SUMMARY}

Hemochromatosis is a common and relatively simple genetic disease to diagnose and treat. It can be diagnosed and treated by family physicians using transferrin saturation, serum ferritin and C282Y genetic testing. Physicians who are not comfortable with interpretation of the genetic test and subsequent family counselling should refer to local specialists and try to avoid any perpetration of misinformation.
13. Bhavnani M, Lloyd D, Marples J, Pendry K, Worwood M. Targeted screening for genetic haemochromatosis: A combined phenotype/genotype approach. J Clin Pathol 2006;59:501-4.

14. Wong K, Adams PC. The diversity of liver diseases among outpatient referrals for an elevated serum ferritin. Can J Gastroenterol 2006;20:467-70.

15. Tung BY, Emond MJ, Bronner MP, Raaka SD, Cotler SJ, Kowdley KV. Hepatitis C, iron status, and disease severity: Relationship with HFE mutations. Gastroenterology 2003;124:318-26.

16. Beaton MD, Adams PC. Prognostic factors and survival in patients with hereditary hemochromatosis and cirrhosis. Can J Gastroenterol 2006;20:257-60.

17. Fletcher LM, Dixon JL, Purdie DM, Powell LW, Crawford DH. Excess alcohol greatly increases the prevalence of cirrhosis in hereditary hemochromatosis. Gastroenterology 2002;122:281-9.

18. Adams PC, Walker AP, Acton RT. A primer for predicting risk of disease in HFE-linked hemochromatosis. Genet Test 2001;5:311-6.

19. Power TE, Adams PC. Psychosocial impact of C282Y mutation testing for hemochromatosis. Genet Test 2001;5:107-10.

20. Anderson RT, Press N, Tucker DC, et al. Patient acceptability of genotypic testing for hemochromatosis in primary care. Genet Med 2005; 7:557-63

21. Delatycki MB, Allen KJ, Nisselle AE, et al. Use of community genetic screening to prevent HFE-associated hereditary hemochromatosis. Lancet 2005;366:314-6.

22. Greenwood DC, Cade JE, Moreton JA, et al. HFE genotype modifies the influence of heme iron intake on iron status. Epidemiology 2005;16:802-5.

23. Bridle KR, Frazer DM, Wilkins SJ, et al. Disrupted hepcidin regulation in HFE-associated haemochromatosis and the liver as a regulator of body iron homoeostasis. Lancet 2003;361:669-73.

24. Leggett BA, Brown NN, Bryant SJ, Duplock L, Powell LW, Halliday JW. Factors affecting the concentrations of ferritin in serum in a healthy Australian population. Clin Chem 1990;36:1350-5. 
25. Adams PC, Gregor J. Hemochromatosis and yersiniosis. Can J Gastroenterol 1990;4:160-2.

26. Lynch SR, Cook JD. Interaction of vitamin C and iron. Ann N Y Acad Sci 1980;355:32-44.

27. Adams PC, Deugnier Y, Moirand R, Brissot P. The relationship between iron overload, clinical symptoms, and age in 410 patients with genetic hemochromatosis. Hepatology 1997;25:162-6.

28. Andersen RV, Tybjaerg-Hansen A, Appleyard M, Birgens H, Nordestgaard BG. Hemochromatosis mutations in the general population: Iron overload progression rate. Blood 2004;103:2914-9.

29. Kowdley KV, Brandhagen DJ, Gish RG, et al; National Hemochromatosis Transplant Registry. Survival after liver transplantation in patients with hepatic iron overload:
The National Hemochromatosis Transplant Registry. Gastroenterology 2005;129:494-503.

30. Yang Q, McDonnell SM, Khoury MJ, Cono J, Parrish RG. Hemochromatosis-associated mortality in the United States from 1979 to 1992: An analysis of Multiple-Cause Mortality Data. Ann Intern Med 1998;129:946-53.

31. Powell LW, Dixon JL, Ramm GA, et al. Screening for hemochromatosis in asymptomatic subjects with or without a family history. Arch Intern Med 2006;166:294-301.

32. Adams PC, Kertesz AE, Valberg LS. Rate of iron reaccumulation following iron depletion in hereditary hemochromatosis. Implications for venesection therapy. J Clin Gastroenterol 1993;16:207-10.

33. Power TE, Adams PC. Hemochromatosis patients as voluntary blood donors. Can J Gastroenterol 2004;18:393-6. 


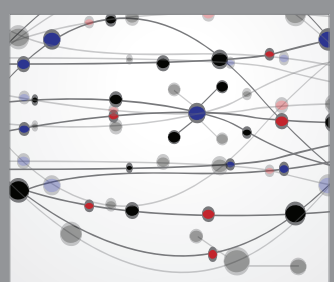

The Scientific World Journal
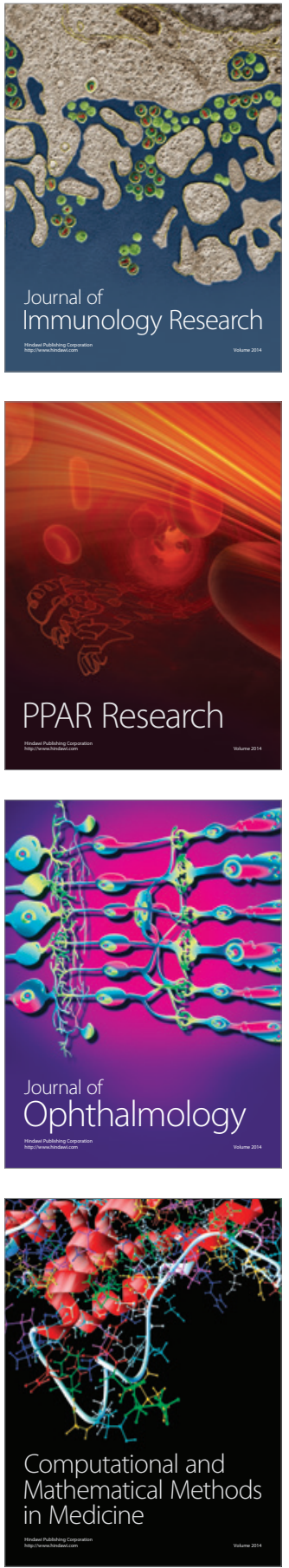

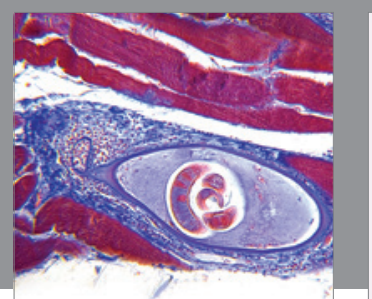

Gastroenterology Research and Practice

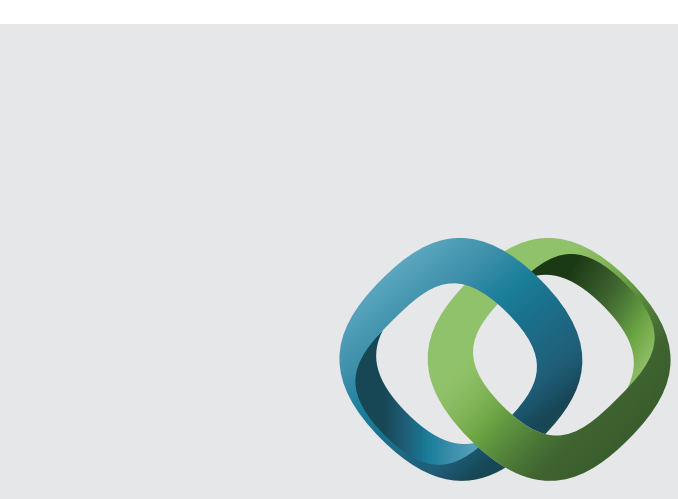

\section{Hindawi}

Submit your manuscripts at

http://www.hindawi.com
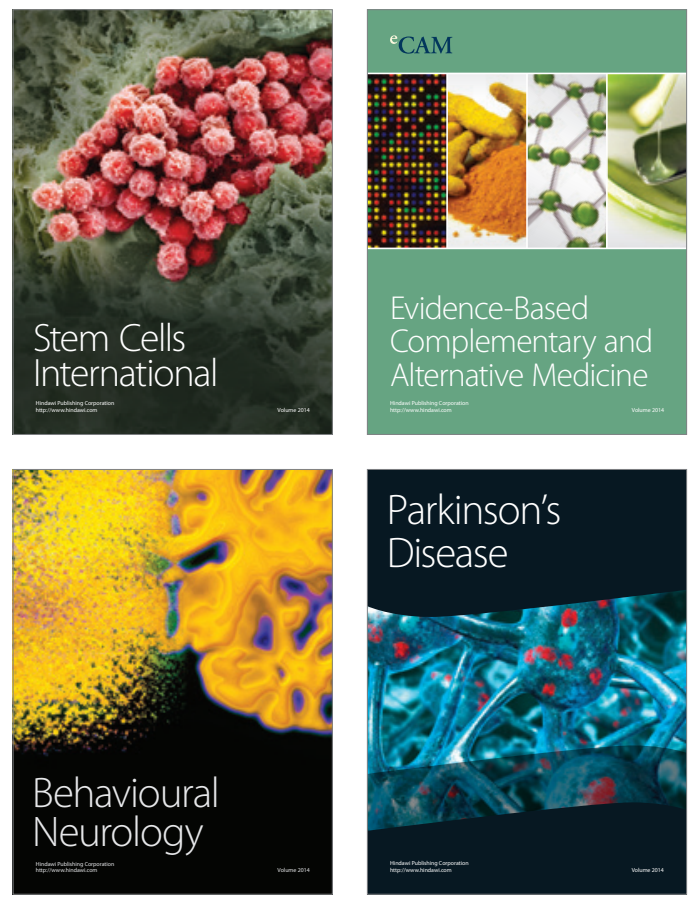
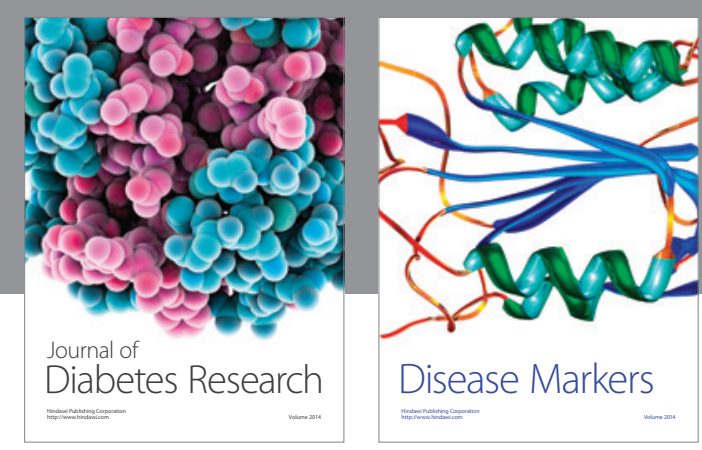

Disease Markers
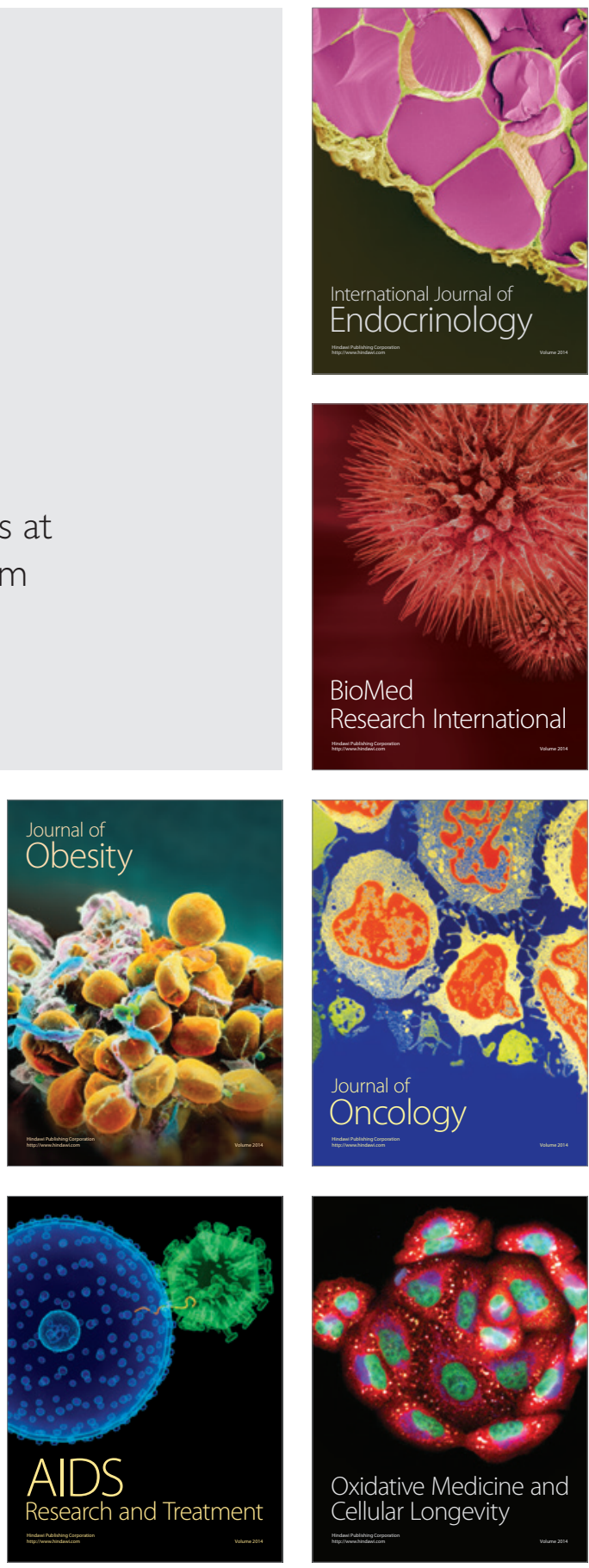